\title{
Microorganisms and clean energy
}

\author{
Timothy Donohue and Richard Cogdell discuss how microbiology can contribute towards \\ the provision of clean solutions to the world's energy needs.
}

Conservative estimates predict that the world's energy needs will increase approximately three-fold by the end of this century. Society's reliance on fossil fuels for this energy represents one of the major challenges to global environmental sustainability and economic stability. Fossil-fuel combustion is also a main source of 'greenhouse gas' and chemicals that have been implicated in numerous health problems. Consequently, there are calls from governments, the private sector and the scientific community to develop alternative energy sources that couple reductions in the use of fossil fuels with decreased greenhouse gas emissions. We contend that microbiology - and photosynthetic microorganisms in particular - can help provide solutions to this energy challenge.

Photosynthetic microorganisms can capture solar energy, a free, abundant and under-used energy source. The amount of solar energy that strikes the Earth every hour $\left(\sim 4.3 \times 10^{20}\right.$ Joules $)$ is approximately equal to the total amount of energy that is consumed on the planet every year $\left(\sim 4.1 \times 10^{20}\right.$ Joules $)$. Therefore, capturing even a small fraction of the available solar energy could make a significant contribution to global energy needs. Despite its availability, however, a study carried out in 2001 found that sunlight provided less than $0.1 \%$ of the world's electricity.

Historically, the study of photosynthetic microorganisms has provided seminal, Nobel-prize-winning insights into how cells harvest solar energy and use it to convert greenhouse gases like carbon dioxide into sugars. We now have an opportunity to leverage our understanding of photosynthesis to produce bioenergy products in a clean and sustainable manner. For example, the 3D crystal structure of photosystem II from the cyanobacterium Thermosynechococcus elongatus provides a detailed view of the water-splitting apparatus that could be used as a basis to produce hydrogen from water ${ }^{1,2}$. For decades, we have known that anaerobic photosynthetic bacteria can use the excess reducing power produced in the light to evolve hydrogen ${ }^{3}$. In addition, photosynthetic microorganisms can be used to power solar-driven microbial fuel cells $s^{4}$. The metabolic capabilities of photosynthetic microorganisms could also be redirected to generate high-energy chemicals (such as alcohols, alkanes and fats) that currently serve as feedstocks for the chemical industries ${ }^{5}$.

Moreover, there are billions of microorganisms populating every niche of the Earth, many of which have untapped potential to help solve the global energy challenge. To grow in unusual environments, microorganisms have evolved unique metabolic strategies to extract energy from the available nutrients and to generate various potentially useful byproducts. In many cases, these microorganisms function cooperatively in communities where their concerted activities perform functions that would not be possible in the absence of their partners.

The development of microbial 'biorefineries' will require significant additional biochemical, genetic, metabolic and ecological insights into the relevant microorganisms. It is essential to acquire a systemslevel understanding of energy capture and its transformation in order to direct the reaction products into pathways that produce alternative fuels or sequester greenhouse gases. Additional research is required to ascertain whether communities of photosynthetic and non-photosynthetic bacteria could be tapped to provide clean energy or replace fossil-fuel-derived feedstocks. Of course, it will also be necessary to find economically viable biorefinery options, optimize the processes involved, and scale-up the systems.

We contend that microbiology can and should make a significant contribution towards satisfying the global need for clean, alternative energy sources. To achieve this goal, there is an urgent need for research aimed at harnessing the capabilities of photosynthetic and other microbial systems. The US Department of Energy has issued a call for Bioenergy Centers to develop microbialbased strategies that generate alternative energy sources from biomass, sunlight and other renewable resources. In addition, the European Science Foundation is considering a major funding initiative to support bio-inspired solar energy strategies. These programmes and private sector initiatives represent an exciting beginning to a long-term concerted effort to develop clean microbial solutions to the world's energy challenge.

\footnotetext{
. Ferreira, K. N., Iverson, T. M., Maghlaoui, K., Barber, J. \& Iwata, S. Architecture of the photosynthetic oxygen-evolving center. Science 303, 1831-1838 (2004).

2. Loll, B., Kern, J., Saenger, W., Zouni, A. \& Biesiadka, J. Towards complete cofactor arrangement in the $3.0 \AA$ A resolution structure of photosystem II. Nature 438, 1040-1044 (2005).

3. Gest, H. \& Kamen, M. Photoproduction of molecular hydrogen by Rhodospirillum rubrum. Science 109, 558 (1949).

4. Gorby, Y. A. et al. Electrically conductive bacterial nanowires produced by Shewanella oneidensis strain MR-1 and other microorganisms. Proc. Natl Acad. Sci. USA 103, 11358-11363 (2006).

5. Lane, N. Batteries not included. What can't bacteria do? Nature $\mathbf{4 4 1}$, 274-277 (2006).
} 